\title{
A practical approach to acromegaly management in Latin America
}

\author{
Marcello D. Bronstein • Oscar D. Bruno • \\ Alin Abreu • Ruth Mangupli $\cdot$ Moisés Mercado
}

Published online: 21 November 2013

(c) The Author(s) 2013. This article is published with open access at Springerlink.com

\begin{abstract}
Introduction Evidence-based treatment guidelines have undoubtedly advanced medical practice and supported optimal management of acromegaly, but their application may be hampered by limited access to the latest treatment options.

Methods In this retrospective, narrative review, the authors revisited existing treatment guidelines for acromegaly in Latin America. These were considered in conjunction with published evidence chosen at the authors' discretion.

Findings In a socially and economically diverse region, such as Latin America, any regional practice guidelines need to appreciate that recommended treatment options, such as
\end{abstract}

M. D. Bronstein $(\bowtie)$

Neuroendocrine Unit, Division of Endocrinology and

Metabolism, Hospital das Clínicas, University of São Paulo

Medical School, Av. Dr. Eneas de Carvalho, 255, $7^{\circ}$ andar, sala

7037, São Paulo CEP 05403-000, Brazil

e-mail: mdbronstein@uol.com.br

O. D. Bruno

Division of Endocrinology, Hospital de Clínicas, University of Buenos Aires, Buenos Aires, Argentina

A. Abreu

Endocrinología, Centro Médico Imbanaco Cali, Cali, Colombia

R. Mangupli

Section of Neuroendocrinology, Department of Neurosurgery,

Hospital Universitario, Caracas, Venezuela

M. Mercado

Faculty of Medicine, Universidad Nacional Autónoma de México, Mexico City, Mexico

M. Mercado

Head Endocrine Service, and Experimental Endocrinology Unit, Hospital de Especialidades, Centro Médico Nacional Siglo XXI, Instituto Mexicano del Segero Social, Mexico City, Mexico surgery by expert pituitary surgical teams and drug therapies, especially somatostatin analogs, are often not available due to limited resources. In these instances, physicians may be obliged to apply less effective therapeutic options.

Conclusions The current article looks at the practical aspects of acromegaly management in Latin America and discusses this in the context of existing guidelines. Furthermore, we consider potential strategies to make better use of resources through combination and multimodal approaches to treatment.

Keywords Acromegaly - Latin America . Somatostatin analogs - Dopamine agonists . Pegvisomant · Guidelines

\section{Introduction}

Diagnosing and managing acromegaly can be a challenge, even in situations where clinicians have access to all the latest diagnostic and treatment modalities (see other articles in this issue [1-4]). This can be complicated further if diagnosis is delayed and/or access to healthcare resources is limited. Failure to identify acromegaly early and to provide optimal disease management often can lead to significant morbidity, severely impaired quality of life and reduced life-expectancy.

Latin America (with between 550 and 600 million people in total) is a region with wide variations in development, poverty, income inequality, literacy, and life expectancy both between and within individual countries [5]. National health care systems in Latin American countries also vary widely in their organizational structure and provision of healthcare services [6]. Access to healthcare resources varies widely not only among countries, but also within countries and even within cities or provinces. 
Economic considerations to prioritize resource allocation decisions are increasingly being used in Latin America, but the use and application of formal Health Economic Evaluations or Health Technology Assessments remains suboptimal [6, 7]. Although countries previously relied on technology assessment reports from outside the Latin America region, there is increasing use of region-specific reports, which are considered more relevant [6].

Evidence-based treatment guidelines have undoubtedly advanced medical practice and supported optimal prescribing for acromegaly, but tend to be developed within the context of optimal access to the latest treatment options. Against this background of diversity and disparity in Latin America, any regional practice guidelines for the management of acromegaly need to appreciate that the recommended options may often not be available due to limited resources.

\section{Epidemiology of acromegaly in Latin America}

Although epidemiologic data are relatively limited over the Latin America region as a whole, national acromegaly registries are starting to provide a reliable picture of diagnostic and treatment patterns, as well estimates for the prevalence of the disease [8, 9]. For instance, the Mexican Acromegaly Registry (EpiAcro), which now includes over 1,400 patients, gives an estimated prevalence of 14 cases per million, which is lower than other parts of the world, suggesting under diagnosis $[8,9]$. Time between onset and diagnosis ranged from 5 to 17 years, and approximately one-third of patients had an invasive tumor at diagnosis. Pituitary surgery was the most common primary treatment option (73\% of patients), whereas radiosurgery was the primary treatment option in only $3 \%$. The remainder received pharmacological therapy with somatostatin analogs (SSAs) $(15 \%)$ or dopamine agonists $(9 \%)$. Approximately $60 \%$ of patients undergoing primary surgery did not achieve biochemical remission and required secondary therapy. For secondary treatment, $36 \%$ had radiosurgery, $36 \%$ received SSAs, $19 \%$ received dopamine agonists and $26 \%$ had surgery. The latest data suggest that $34 \%$ of patients in the registry are in biochemical remission, $40 \%$ have active disease and $27 \%$ are stable on pharmacological therapy.

\section{Guidelines for the management of acromegaly}

Since 2000, the Acromegaly Consensus Group has developed several international guidelines and consensus statements regarding the management of acromegaly [10-14]. The latest major update to these guidelines was published in 2009, based upon evidence available in 2007 , and a further consensus on diagnosis and treatment of acromegaly complications was published in 2012 [14, 15]. A meeting held in Mexico City in 2007 led to expert panel recommendations on the management of acromegaly specifically in Latin America, and these were published in 2010 [16]. Guidelines have also been developed at the national level in Mexico and Brazil $[17,18]$.

All the latest versions of these guidelines and consensus statements generally recommend either surgery or, if there is a low probability of surgical cure, SSAs as primary therapy in acromegaly (see Fig. 1 for the algorithm developed by the Latin American Expert Panel [16]). The SSAs are considered the pharmacological treatment of choice because they fulfill all the requirements for the primary treatment of acromegaly by reducing tumor volume, controlling disease symptoms and achieving biochemical control in the majority of patients. Nevertheless, it should be pointed out that the best results were obtained in patients with mild-to-moderate serum GH elevation. Furthermore, a selection bias could occur in retrospective studies due to the withdrawal of unresponsive patients. Evidence to support the use of SSAs as the primary pharmacological therapeutic option is now extensive and includes several studies involving Latin American populations [19-23]. Furthermore, all the guidelines generally recommend SSA therapy as the next line of treatment in patients with insufficiently controlled $\mathrm{GH}$ secretion after surgery.

In the settings above, dopamine agonists (principally cabergoline) are generally reserved for patients with relatively low GH and IGF-I concentrations or those in whom an oral drug is preferred over injectable therapy (as is the case for all SSA formulations). The GH receptor antagonist pegvisomant is generally reserved for third-line therapy. Radiosurgery is considered to be an option in selected cases when no disease control is achieved with surgery and pharmacological therapy, especially if pegvisomant is not available.

While considering the recommendations highlighted above, one key issue raised by the Latin American Panel is that of limited access to resources at the local level [16]. This message was reinforced repeatedly by the Panel, e.g.:

- "Since not all the diagnostic tools and treatment options are available in all Latin American countries, physicians need to adapt their clinical management decisions to the available local resources and therapeutic options".

- "...treatment of patients with acromegaly in Latin America is influenced by local issues of cost, availability and expertise of pituitary neurosurgeons, which should dictate therapeutic choices."

- "...a range of management approaches may not be available for many patients with acromegaly and the feasibility and cost should be considered in the implementation of local guidelines." 
Fig. 1 Treatment algorithm for choosing first-line therapy in Latin American patients with newly diagnosed acromegaly (a) or those uncontrolled after surgery and SSAs (b). *Because pegvisomant is not available in all Latin American countries, radiotherapy might be considered as an additional treatment option for patients not controlled after maximal doses of somatostatin analogs and/or cabergoline. (Reproduced with permission from [16])
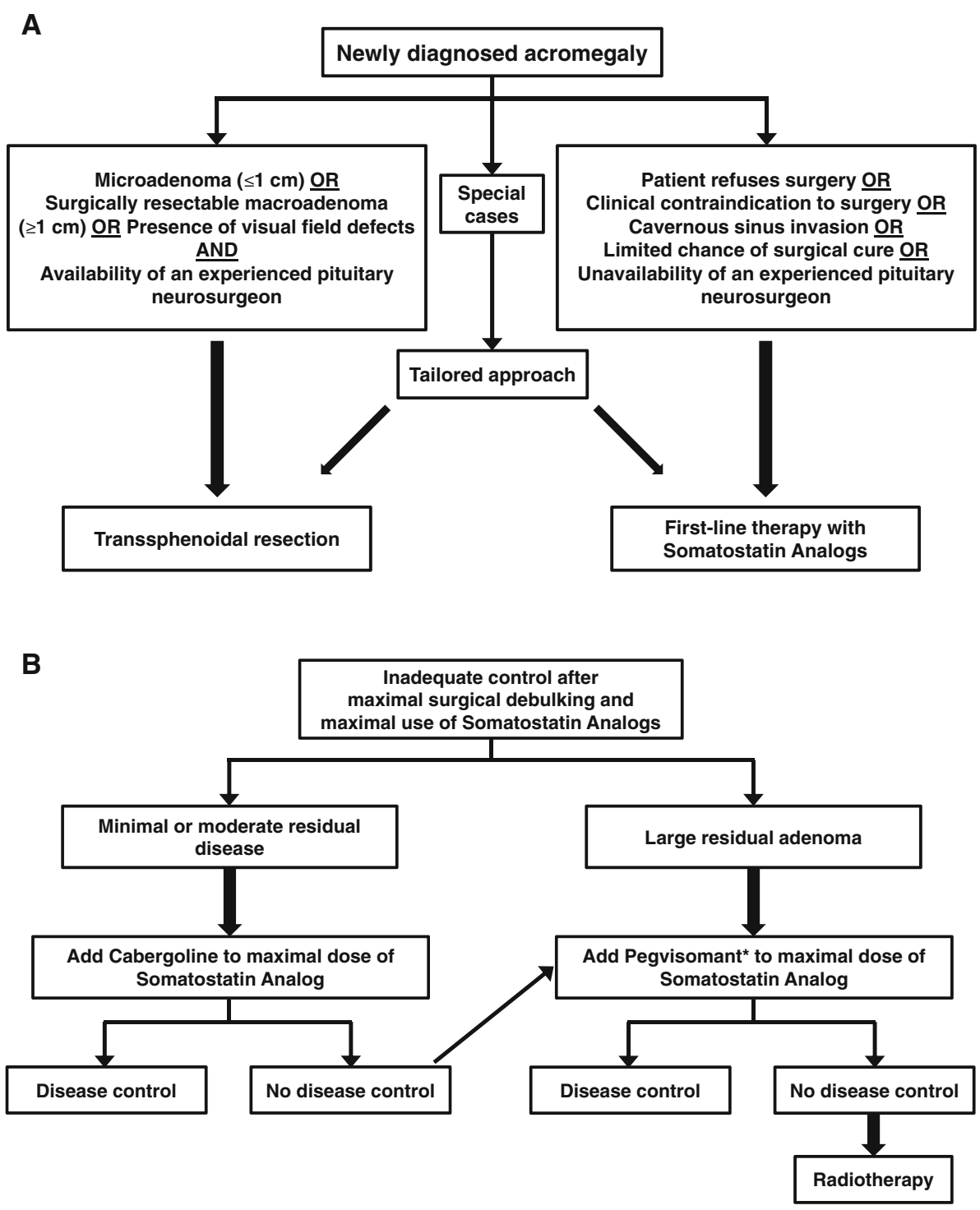

- "Access to SSAs is a key issue in Latin America, as treatment is not always subsidized by government agencies."

- "Physicians in Latin America should tailor appropriate treatments or combinations for each patient based on the clinical presentation and availability of resources".

- "...judgment is required to indicate the first-line therapy, taking into account the local experience and availability of resources."

\section{Revisiting the expert panel recommendations on the management of acromegaly in Latin America}

Little has changed in terms of new therapies in the market since the publication of those recommendations (although there may have been changes in access to individual therapeutic options at the local level). However, guidance was minimal regarding the best approach to take in cases where access to resources is restricted, although it was noted that "Radiotherapy may be indicated in selected cases.... when local issues of cost preclude other therapies." The preceding section summarizes the broad consensus panel efforts regarding recommendations for the management of acromegaly in Latin America. The following sections provide our own suggestions on how to gain the most benefit from available resources within the context of those recommendations. This may assist in providing a more practical, relevant and flexible approach to acromegaly treatment across Latin America.

In view of the recommendations that SSAs generally represent the first-choice pharmacological therapy in acromegaly, it is worth highlighting the way in which this therapy can be optimized and costs reduced [24]. Addition of 
cabergoline (a less effective, but also less expensive oral agent that is widely available in Latin America) may improve response in patients uncontrolled with SSAs alone, thus improving the cost-effectiveness of these agents [2427]. Although pegvisomant is expensive, requires daily injections and has only limited availability across Latin America, it can be effective as add-on therapy in partial responders to SSAs and there are several other potential advantages to using this combination in selected patients [24, 28, 29]. For instance pegvisomant/SSA combination therapy may be associated with 1) improved insulin sensitivity and quality of life compared with using SSAs alone, 2) better control of tumor size compared with pegvisomant alone, and 3) reduced pegvisomant doses and thus cost savings [24, 28, 29]. For acromegalic women with mild IGF1 elevation, estrogens represent an inexpensive alternative to pegvisomant, as they act as a post-receptor noncompetitive GH antagonist by stimulating hepatic socs 2 ; however, the risk of thrombosis should be taken into account [30].

In centers with sufficient surgical expertise, surgical reduction of tumor mass can improve the outcome of SSA treatment in acromegalic patients resistant to primary therapy with SSAs [24, 31]; similarly, SSA treatment may improve surgical outcomes [32]. Nevertheless, access to skilled surgeons should not dictate the choice of therapy, if pharmacological treatment is indicated. In well-controlled patients, it may be possible to increase the interval between doses without losing efficacy [33]. In a small subset of patients, it may also be possible to permanently discontinue SSA therapy, suggesting that these agents might provide permanent beneficial functional changes in $\mathrm{GH}$ release (at least in some patients) [34].

Cabergoline may be seen as an alternative (albeit less effective) low-cost pharmacological treatment in situations where SSAs are not available. However, it should be emphasized that this remains a suboptimal first choice and health authorities should be encouraged to improve access to recommended pharmacological therapies (i.e., SSAs). Radiosurgery and modern external beam radiotherapy can be an effective, low-cost and reasonably safe means of controlling acromegalic activity, although it has a long efficacy latency period [35, 36]. However, it should be emphasized that the choice of radiation techniques must be based on tumor characteristics and if possible should be performed using stereotactic devices [37]. Therefore, health authorities should be aware of the cost/benefit ratio of less efficacious therapies, which, albeit leading to potential savings, may be hampered by the social and economic burden of co-morbidities present in uncontrolled acromegalic patients, as well as, in the case of radiotherapy, the costs of full pituitary hormone replacement in the frequent cases of progression to panhypopituitarism.

\section{Other factors that may contribute to improved care in acromegaly in Latin America}

Delayed diagnosis is a problem in many parts of the world, including Latin America [8, 9, 38, 39]. Consequently, many patients present with advanced disease that may not be suitable for surgery, thus limiting treatment options. There is, therefore, a need to increase awareness about acromegaly - this has the potential to increase the chances of early diagnosis and promote early referral to expert centers, thus increasing treatment options, improving longterm outcomes and reducing costs [40]. Education of general practitioners and the adoption of simple screening techniques based on phenotypic alterations may be one cost-effective method for identifying acromegaly early [41]. Medical students, nurses, and the general public may also be good candidates for increased awareness programs.

Implementation of support networks to provide adequate patient follow-up is another important component of acromegaly management. Patients on pharmacological therapy require life-long treatment, but compliance can be poor and many patients will not receive adequate long-term therapy if follow-up support is insufficient [42]. Furthermore, a significant proportion of patients will change their biochemical status during long-term follow-up after surgery and may require a modification of management strategies [43].

Finally, it should be stressed that diagnosis and management of acromegaly is complex and requires the involvement of multidisciplinary expert teams. As such, the comprehensive care, education and support of patients with acromegaly are best carried out in designated Pituitary Centers of Excellence (COE) [44]. Increasing access to COEs across Latin America is thus a key aspect of improving care in the region.

\section{Conclusions}

One of the greatest challenges in providing consensus recommendations regarding the management of acromegaly in Latin America is the diversity of access to treatment and reimbursement policies across this large population of between 550 and 600 million. The wide variations in access to healthcare resources across Latin America, which may manifest in terms of access to surgical and/or pharmacological resources and the availability of adequate patient support networks, make it difficult to provide pan-regional recommendations for the management of acromegaly.

In some countries, the availability and cost of SSAs and other drugs, such as pegvisomant, as well as the availability of surgical expertise, are critical issues. Thus, some key recommendations can only be followed when these 
resources are available and physicians may be obliged to apply therapeutic options that are not indicated by the international guidelines.

In the absence of access to first line recommended pharmacological therapy (i.e., SSAs), physicians may have to rely on less expensive, less effective drugs (most notably cabergoline) or other less well-tolerated treatment modalities (e.g., radiosurgery). Nevertheless, opportunities exist for more flexible use of first choice therapies, such as SSAs, in order to optimize treatment and reduce costs, although economic outcome data are lacking. There is also a common need across countries to increase awareness about acromegaly - this could improve early diagnosis and lead to improved outcomes and reduced costs.

In conclusion, delayed diagnosis and limited access to healthcare resources can compromise optimal management of patients with acromegaly. This situation may be particularly notable in parts of Latin America due to the economic and social diversity across the region. Although opportunities exist to improve management through optimal use of existing limited healthcare resources, there is a need for increased access to recommended therapies, especially SSAs. Furthermore, the creation of regional acromegaly patient registries, such as EpiAcro, should help to improve understanding of diagnostic and therapeutic trends in different regions of Latin America.

Acknowledgments The Latin American Knowledge Network Initiative, including meetings and preparation of this supplement, was organized and funded by Ipsen. Medical writing support was provided by Patrick Covernton on behalf of Arsenal-CDM Paris and funded by Ipsen. The authors were fully responsible for the concept and all content, were involved at all stages of manuscript development, and provided approval of the final version for submission.

Open Access This article is distributed under the terms of the Creative Commons Attribution License which permits any use, distribution, and reproduction in any medium, provided the original author(s) and the source are credited.

\section{References}

1. de los Monteros ALE, Carrasco CA, Albarrán AAR, Gadelha M, Abreu A, Mercado M (2013) The role of primary pharmacological therapy in acromegaly. Pituitary. doi:10.1007/s11102-0130530-0

2. Vilar L, Valenzuela A, Ribeiro-Oliveira A Jr, Gómez Giraldo CM, Pantoja D, Bronstein MD (2013) Multiple facets in the control of acromegaly. Pituitary. doi:10.1007/s11102-013-0536-7

3. Guitelman M, Abreu A, Espinosa-de-los-Monteros AL, Mercado M (2013) Patient-focussed outcomes in acromegaly. Pituitary. doi:10.1007/s11102-013-0519-8

4. Carrasco CA, Gadelha M, Manavela M, Bruno OD (2013) Aggressive tumors and difficult choices in acromegaly. Pituitary. doi:10.1007/s11102-013-0538-5

5. Barreto SM, Miranda JJ, Figueroa JP, Schmidt MI, Munoz S, Kuri-Morales PP, Silva JB Jr (2012) Epidemiology in Latin
America and the Caribbean: current situation and challenges. Int $\mathrm{J}$ Epidemiol 41(2):557-571

6. Pichon-Riviere A, Augustovski F, García Martí S, Sullivan SD, Drummond M (2012) Transferability of health technology assessment reports in Latin America: an exploratory survey of researchers and decision makers. Int $\mathbf{J}$ Technol Assess Health Care 28(2):180-186

7. Pichon-Riviere A, Augustovski F, Rubinstein A, Martí SG, Sullivan SD, Drummond MF (2010) Health technology assessment for resource allocation decisions: are key principles relevant for Latin America? Int J Technol Assess Health Care 26(4):421-427

8. Acevedo K, Aguilar-Pacheco PE, Arellano Montaño S, BastidasAdrián MY, Domínguez B, García AR, Gómez-Martínez G, González-Estrada J, Hernández A, Hidalgo L, Jervis P, LunaCeballos RI, Maya-Luna M, Mercado M, Vidrio M, Padilla-Retana JA, Portocarrero L, Rangel-Sánchez G, Reza-Albarrán A, Rivera A, Trujillo-Lozoya C, Uribe AM, Velázquez FJ, Vergara A (2010) Primer reporte del registro nacional de acromegalia: Programa "Epiacro". Revista de Endocrinología y Nutrición 18(4):176-180

9. Jervis P, Trujillo C, Portocarrero L, Domínguez B, Vidrio M, Luna-Ceballos RI, Reza A, Velázquez F, Maya-Luna ML, Gómez G, Acevedo K, García R, Mercado M (2012) "Epiacro": The Mexican Acromegaly Registry [Abstract]. Endocr Rev 33(03_MeetingAbstracts): MON-717

10. Giustina A, Barkan A, Casanueva FF, Cavagnini F, Frohman L, Ho K, Veldhuis J, Wass J, Von Werder K, Melmed S (2000) Criteria for cure of acromegaly: a consensus statement. J Clin Endocrinol Metab 85(2):526-529

11. Melmed S, Casanueva FF, Cavagnini F, Chanson P, Frohman L, Grossman A, Ho K, Kleinberg D, Lamberts S, Laws E, Lombardi G, Vance ML, Werder KV, Wass J, Giustina A (2002) Guidelines for acromegaly management. J Clin Endocrinol Metab 87: $4054-4058$

12. Giustina A, Casanueva FF, Cavagnini F, Chanson P, Clemmons D, Frohman LA, Gaillard R, Ho K, Jaquet P, Kleinberg DL, Lamberts SW, Lombardi G, Sheppard M, Strasburger CJ, Vance ML, Wass JA, Melmed S (2003) Pituitary society and the European neuroendocrine Association. Diagnosis and treatment of acromegaly complications. J Endocrinol Invest 26(12): 1242-1247

13. Giustina A, Barkan A, Chanson P, Grossman A, Hoffman A, Ghigo E, Casanueva F, Colao A, Lamberts S, Sheppard M, Melmed S (2008) Guidelines for the treatment of growth hormone excess and growth hormone deficiency in adults. J Endocrinol Invest 31(9):820-838

14. Acromegaly Consensus Group, Melmed S, Colao A, Barkan A, Molitch M, Grossman AB, Clemmons D, Chanson P, Laws E, Schlechte J, Vance ML, Ho K, Giustina A (2009) Guidelines for acromegaly management: an update. J Clin Endocrinol Metab 94(5):1509-1517

15. Melmed S, Casanueva FF, Klibanski A, Bronstein MD, Chanson P, Lamberts SW, Strasburger CJ, Wass JA, Giustina A (2013) A consensus on the diagnosis and treatment of acromegaly complications. Pituitary 16(3):294-302

16. Barkan A, Bronstein MD, Bruno OD, Cob A, Espinosa-de-losMonteros AL, Gadelha MR, Garavito G, Guitelman M, Mangupli R, Mercado M, Portocarrero L, Sheppard M (2010) Management of acromegaly in Latin America: expert panel recommendations. Pituitary 13(2):168-175

17. Arellano S, Aguilar P, Domínguez B, de Los E, Monteros AL, González Virla B, Sosa E, Mercado M, Guinto G, Martínez I, Hernández E, Reza A, Portocarrero L, Vergara A, Velázquez FJ, Ramírez E (2007) Segundo Consenso Nacional de Acromegalia: recomendaciones para su diagnóstico, tratamiento y seguimiento. Revista de Endocrinología y Nutrición 15(3 Suppl 1):S7-S16 
18. Vieira Neto L, Abucham J, Araujo LA, Boguszewski CL, Bronstein MD, Czepielewski M, Jallad RS, Musolino NR, Naves LA, Ribeiro-Oliveira Júnior A, Vilar L, Faria Mdos S, Gadelha MR (2011) Recommendations of Neuroendocrinology Department from Brazilian Society of Endocrinology and Metabolism for diagnosis and treatment of acromegaly in Brazil. Arq Bras Endocrinol Metabol 55(2):91-105

19. Mangupli R, Lisette A, Ivett C, Paul C, de los Ríos Victoria C, Luis CJ (2003) Improvement of acromegaly after octreotide LAR treatment. Pituitary 6(1):29-34

20. Jallad RS, Musolino NR, Salgado LR, Bronstein MD (2005) Treatment of acromegaly with octreotide-LAR: extensive experience in a Brazilian institution. Clin Endocrinol 63(2):168-175

21. Mercado M, Borges F, Bouterfa H, Chang TC, Chervin A, Farrall AJ, Patocs A, Petersenn S, Podoba J, Safari M, Wardlaw J; SMS995B2401 Study Group (2007) A prospective, multicentre study to investigate the efficacy, safety and tolerability of octreotide LAR (long-acting repeatable octreotide) in the primary therapy of patients with acromegaly. Clin Endocrinol 66(6):859-868

22. Murray RD, Melmed S (2008) A critical analysis of clinically available somatostatin analog formulations for therapy of acromegaly. J Clin Endocrinol Metab 93(8):2957-2968

23. Sosa E, Espinosa-de-los-Monteros AL, González B, Vargas G, Mier F, Mercado M (2008) Treatment of acromegaly with octreotide LAR. Rev Med Inst Mex Seguro Soc 46(6):651-658

24. Bronstein MD (2010) Optimizing acromegaly treatment. Front Horm Res 38:174-183

25. Jallad RS, Bronstein MD (2009) Optimizing medical therapy of acromegaly: beneficial effects of cabergoline in patients uncontrolled with long-acting release octreotide. Neuroendocrinology 90(1):82-92

26. Mattar P, Alves Martins MR, Abucham J (2010) Short- and longterm efficacy of combined cabergoline and octreotide treatment in controlling IGF-I levels in acromegaly. Neuroendocrinology 92(2):120-127

27. Vilar L, Azevedo MF, Naves LA, Casulari LA, Albuquerque JL, Montenegro RM, Montenegro RM Jr, Figueiredo P, Nascimento GC, Faria MS (2011) Role of the addition of cabergoline to the management of acromegalic patients resistant to long-term treatment with octreotide LAR. Pituitary 14(2):148-156

28. Neggers SJ, de Herder WW, Janssen JA, Feelders RA, van der Lely AJ (2009) Combined treatment for acromegaly with longacting somatostatin analogs and pegvisomant: long-term safety for up to 4.5 years (median 2.2 years) of follow-up in 86 patients. Eur J Endocrinol 160(4):529-533

29. van der Lely AJ, Bernabeu I, Cap J, Caron P, Colao A, Marek J, Neggers S, Birman P (2011) Coadministration of lanreotide Autogel and pegvisomant normalizes IGF1 levels and is well tolerated in patients with acromegaly partially controlled by somatostatin analogs alone. Eur J Endocrinol 164(3):325-333

30. Shimon I, Barkan A (2012) Estrogen treatment for acromegaly. Pituitary 15(4):601-607
31. Jallad RS, Musolino NR, Kodaira S, Cescato VA, Bronstein MD (2007) Does partial surgical tumour removal influence the response to octreotide-LAR in acromegalic patients previously resistant to the somatostatin analogue? Clin Endocrinol 67(2):310-315

32. Mao ZG, Zhu YH, Tang HL, Wang DY, Zhou J, He DS, Lan H, Luo BN, Wang HJ (2010) Preoperative lanreotide treatment in acromegalic patients with macroadenomas increases short-term postoperative cure rates: a prospective, randomised trial. Eur $\mathrm{J}$ Endocrinol 162(4):661-666

33. Abrams P, Alexopoulou O, Abs R, Maiter D, Verhelst J (2007) Optimalization and cost management of lanreotide-Autogel therapy in acromegaly. Eur J Endocrinol 157(5):571-577

34. Ramírez C, Vargas G, González B, Grossman A, Rábago J, Sosa E, Espinosa-de-Los-Monteros AL, Mercado M (2012) Discontinuation of octreotide LAR after long term, successful treatment of patients with acromegaly: is it worth trying? Eur $\mathrm{J}$ Endocrinol 166(1):21-26

35. Jallad RS, Musolino NR, Salgado LR, Bronstein MD (2007) Treatment of acromegaly: is there still a place for radiotherapy? Pituitary 10(1):53-59

36. González B, Vargas G, Espinosa-de-los-Monteros AL, Sosa E, Mercado M (2011) Efficacy and safety of radiotherapy in acromegaly. Arch Med Res 42(1):48-52

37. Minniti G, Scaringi C, Amelio D, Maurizi Enrici R (2012) Stereotactic irradiation of $\mathrm{GH}$-secreting pituitary adenomas. Int $\mathrm{J}$ Endocrinol 2012:482861

38. Reid TJ, Post KD, Bruce JN, Nabi Kanibir M, Reyes-Vidal CM, Freda PU (2010) Features at diagnosis of 324 patients with acromegaly did not change from 1981 to 2006: acromegaly remains under-recognized and under-diagnosed. Clin Endocrinol 72(2):203-208

39. Psaras T, Milian M, Hattermann V, Freiman T, Gallwitz B, Honegger J (2011) Demographic factors and the presence of comorbidities do not promote early detection of Cushing's disease and acromegaly. Exp Clin Endocrinol Diabetes 119(1):21-25

40. Knutzen R, Ezzat S (2006) The cost of medical care for the acromegalic patient. Neuroendocrinology 83(3-4):139-144

41. Rosario PW, Calsolari MR (2012) Screening for acromegaly by application of a simple questionnaire evaluating the enlargement of extremities in adult patients seen at primary health care units. Pituitary 15(2):179-183

42. Kasuki L, Marques NV, Nuez MJ, Leal VL, Chinen RN, Gadelha MR (2013) Acromegalic patients lost to follow-up: a pilot study. Pituitary 16(2):245-250

43. Espinosa-de-los-Monteros AL, Sosa E, Cheng S, Ochoa R, Sandoval C, Guinto G, Mendoza V, Hernández I, Molina M, Mercado M (2006) Biochemical evaluation of disease activity after pituitary surgery in acromegaly: a critical analysis of patients who spontaneously change disease status. Clin Endocrinol 64(3):245-249

44. McLaughlin N, Laws ER, Oyesiku NM, Katznelson L, Kelly DF (2012) Pituitary centers of excellence. Neurosurgery 71(5):916-924 